\title{
Pengaruh Trial Focal Depth terhadap Kedalaman Sumber Gempa Menggunakan Hypo71pc (Studi Kasus Kegempaan di Sulawesi Utara)
}

\author{
A.M.Miftahul Huda ${ }^{1 *}$ dan Nuruddin Kafy El-Ridlo ${ }^{2}$ \\ ${ }^{1}$ Prodi Teknik Instrumentasi Elektronika Migas, Sekolah Tinggi Teknologi Migas, Balikpapan \\ ${ }^{2}$ Prodi Teknik Perminyakan, Sekolah Tinggi Teknologi Migas, Balikpapan \\ miftahul@sttmigas.ac.id
}

\begin{abstract}
Hypocenter modeling of earthquake events has been carried out in the North Sulawesi region using HYPO71 devices. The process of determining of hypocenter considered to various aspects of reference, one of which is the use of trial focal depth. This research will discuss the influence of these elements in giving iteration results. Seismic data comes from the Meteorology and Geophysics Agency station from 2008-2018 with a magnitude of more than M 6. The Methods of testing is done randomly by taking into account the depth of the data reported. The test results obtained a relatively large influence on the data that gives output and suitability to the position of the earthquake events and its depth. The effect caused by the trial focal depth affects the iterative process in quantity of data processing. Based on root mean square error correlated to uniqueness of the output obtained 5 events with the best conditions
\end{abstract}

Keywords: hypocenter, HYPO71PC, trial focal depth.

\section{ABSTRAK}

Pemodelan hiposenter kejadian gempa telah dilakukan di wilayah Sulawesi utara menggunakan perangkat HYPO71PC. Proses penentuan posisi hiposenter memperhatikan berbagai aspek referensi, salah satunya adalah penggunaan kedalaman fokal uji. Penelitian ini akan membahas pengaruh elemen tersebut dalam memberikan hasil iterasi. Data kegempaan berasal dari stasiun Badan Meteorologi Klimatologi dan Geofisika dari tahun 2008-2018 dengan ketentuan magnitudo lebih dari 6 . Metode pengujian dilakukan secara random dengan memperhatikan data kedalaman terlapor. Hasil pengujian didapatkan pengaruh yang relatif besar terhadap data yang memberikan luaran dan kesesuaian dengan posisi kejadian gempa serta kedalamannya. Efek yang ditimbulkan oleh kedalaman fokal uji mempengaruhi proses iterasi secara kuantitas pemrosesan data. Berdasarkan nilai kesalahan root mean square dan keunikan luaran didapatkan 5 buah kejadian dengan kondisi terbaik.

Kata kunci: hiposenter, HYPO71PC, kedalaman fokal uji. 


\section{PENDAHULUAN}

Penentuan hiposenter menjadi rutinitas utama pemrosesan data kegempaan. Hiposenter dan waktu terjadinya gempa menunjukkan kapan dan di mana sumber terjadinya kegempaan, sehingga menjadi pertimbangan utama dalam proses mitigasi bencana gempa bumi. Hiposenter memiliki tiga variabel yang terkait satu dengan yang lain yaitu latitude, longitude dan kedalaman. Penentuan hiposenter dapat dilakukan dalam dua cara utama yaitu menggunakan metode grafik dan menggunakan metode perhitungan ${ }^{[1]}$. Metode perhitungan biasanya dikaitkan dengan Metode Geiger yang menjadi inti dari berbagai perangkat lunak dan metode untuk memproses data kegempaan, diantaranya adalah HYPO71PC ${ }^{[2]}$ pengembangan dari HYPOINVERSE ${ }^{[3]}$ dan HYPOCENTER ${ }^{[4]}$, metode joint hypocentre determination $(\mathrm{JHD})^{[5]}$, metode modified joint hypocentre determination $(\mathrm{MJHD})^{[6]}$, serta metode inversi simultan hiposenter dan struktur kecepatan gelombang baik untuk 1 dimensi ${ }^{[7]}$ maupun 3 dimensi ${ }^{[8]}$.

Dinyatakan bahwasanya jika kita dapat menentukan secara pasti letak focal depth maka kita dapat menentukan secara tepat hiposenter suatu gempa melalui metode kalkulasi ${ }^{[1]}$. Hanya saja penentuan hiposenter merupakan permasalahan nonlinier yang sangat sukar untuk ditentukan secara pasti parameter-parameter utamanya (lattidude, longitude, kedalaman, waktu), oleh karenanya pada HYPO71PC dilakukan proses linierasisasi terlebih dahulu ${ }^{[2]}$. Dilaporkan pula pengaruh focal depth error (FDE) sebagai bentuk selisih dari perhitungan kedalaman meggunakan fungsi Green dengan kedalaman riil, untuk menentukan momen tensor, dinyatakan bahwa sangat sulit untuk menentukan kedalaman sebuah gempa riil, baik dilakukan secara metode kinematik maupun dinamik sehingga mempengaruhi karakteristik dari sumber gempa ${ }^{[9]}$. Pada HYPO71PC dibutuhkan parameter trial focal depth (TFD) untuk mengiterasi hiposenter suatu gempa. Oleh karena itu dalam artikel ini kami ingin melaporkan hasil pengaruh penggunaan TFD yang digunakan pada HYPO71PC untuk mengestimasi nilai kedalaman riil di lapangan.

\section{METODE}

Penelitian ini menggunakan data rekaman seismik yang didapatkan dari stasiun BMKG untuk gempa dengan skala magnitudo lebih dari 6. Data diolah menggunakan program analisis kegempaan Seismic Analysis Code (SAC) ${ }^{[10]}$ untuk ditentukan waktu tiba gelombang $\mathrm{P}$ dan $\mathrm{S}^{[11]}$. Kemudian data disiapkan beserta parameter-parameter masukan sesuai dengan yang dibutuhkan pada data input HYPO71PC. Program HYPO71PC dijalankan dengan memvariasikan nilai TFD, mulai dari 0,0 km sampai dengan 90,0 km. Berikut merupakan tampilan gelombang seismik 3 komponen dari program SAC untuk menganalisis waktu tempuh gelombang primer (P) dan sekunder (S).

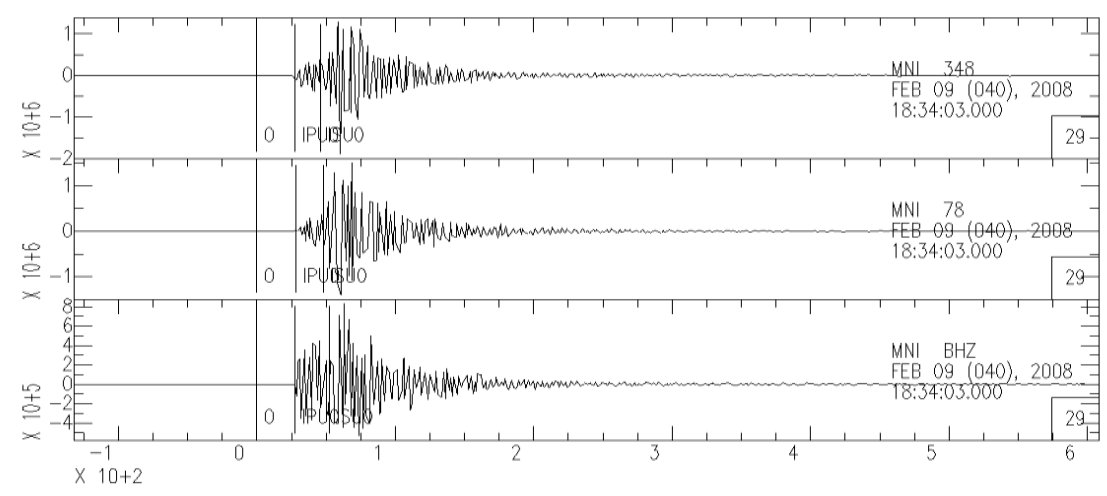

Gambar 1. Tampilan rekaman seismik pada SAC yang telah dilakukan picking waktu tempuh gelombang P dan S untuk kejadian gempa 80209 yang direkam oleh stasiun MNI 
Tampilan rekaman seismik dari BMKG sebagai contoh pada Gambar 1 merupakan rekaman seismik untuk stasiun MNI pada kejadian gempa 80209 yang terdiri dari tiga komponen. Komponen-komponen tersebut yaitu komponen utara-selatan, timur-barat, dan vertikal. Untuk mendapatkan waktu tiba gelombang S yang murni, dilakukan rotasi data, sehingga menjadi komponen radial, transversal, dan vertikal.

\section{HASIL DAN PEMBAHASAN}

Data yang dianalisa sebagaimana ditunjukkan oleh Tabel 1 bahwasanya nilai magnitudo terlapor $\geq 6$ dengan kedalaman terendah adalah $10,0 \mathrm{~km}$ dan terdalam142,0 km di bawah permukaan. Jika dilakukan klasifikasi terhadap data awal menjadi tiga kategori, kedalaman antara 0,0-50,0 km, kedalaman antara 51,0-100,0 km, dan kedalaman di atas 100,0 km maka secara berturut-turut untuk kategori pertama terdapat 6 data, kedua 3 data, dan ketiga 3 data.

Tabel 1. Atribut data penelitian berdasarkan katalog kegempaan BMKG

\begin{tabular}{|c|c|c|c|c|c|c|}
\hline No & Waktu Mula & Mag. & Lat. & Long. & Kedalaman & Wilayah \\
\hline 1 & $\begin{array}{c}\text { 2017-05- } \\
\text { 29T14:35:23 }\end{array}$ & 6,5 & $-1,27$ & 120,45 & 13,0 & Sulawesi, Indonesia \\
\hline 2 & $\begin{array}{c}\text { 2015-03- } \\
\text { 15T23:17:17 }\end{array}$ & 6,0 & $-0,54$ & 122,42 & 29,0 & $\begin{array}{c}\text { Minahassa Peninsula, } \\
\text { Sulawesi }\end{array}$ \\
\hline 3 & $\begin{array}{c}\text { 2014-11- } \\
\text { 15T03:08:05 }\end{array}$ & 6,3 & $-0,23$ & 124,07 & 104,0 & Southern Molucca Sea \\
\hline 4 & $\begin{array}{c}\text { 2014-09- } \\
\text { 10T02:46:10 }\end{array}$ & 6,2 & $-0,18$ & 125,09 & 54,0 & Southern Molucca Sea \\
\hline 5 & $\begin{array}{c}\text { 2012-12- } \\
\text { 17T09:16:32 }\end{array}$ & 6,1 & $-0,72$ & 123,93 & 46,0 & $\begin{array}{c}\text { Minahassa Peninsula, } \\
\text { Sulawesi }\end{array}$ \\
\hline 6 & $\begin{array}{c}\text { 2012-08- } \\
\text { 18T09:41:52 }\end{array}$ & 6,3 & $-1,31$ & 120,11 & 10,0 & Sulawesi, Indonesia \\
\hline 7 & $\begin{array}{c}\text { 2011-12- } \\
\text { 13T07:52:12 }\end{array}$ & 6,0 & 0,07 & 123,15 & 162,0 & $\begin{array}{c}\text { Minahassa Peninsula, } \\
\text { Sulawesi }\end{array}$ \\
\hline 8 & $\begin{array}{c}\text { 2011-02- } \\
\text { 15T13:33:55 }\end{array}$ & 6,2 & $-2,47$ & 121,55 & 34,0 & Sulawesi, Indonesia \\
\hline 9 & $\begin{array}{c}\text { 2010-04- } \\
\text { 05T10:05:48 }\end{array}$ & 6,0 & $-0,13$ & 125,11 & 57,0 & Southern Molucca Sea \\
\hline 10 & $\begin{array}{c}\text { 2008-12- } \\
\text { 11T21:40:53 }\end{array}$ & 6,2 & 0,00 & 123,60 & 142,0 & $\begin{array}{c}\text { Minahassa Peninsula, } \\
\text { Sulawesi }\end{array}$ \\
\hline 11 & $\begin{array}{c}\text { 2008-11- } \\
\text { 16T17:02:34 }\end{array}$ & 7,4 & 1,40 & 122,10 & 39,0 & $\begin{array}{c}\text { Minahassa Peninsula, } \\
\text { Sulawesi }\end{array}$ \\
\hline 12 & $\begin{array}{c}\text { 2008-10- } \\
\text { 20T04:54:20 }\end{array}$ & 6,3 & 0,20 & 120,60 & 108,0 & $\begin{array}{c}\text { Minahassa Peninsula, } \\
\text { Sulawesi }\end{array}$ \\
\hline 13 & $\begin{array}{c}\begin{array}{c}\text { 2008-02- } \\
\text { 09T18:34:03 }\end{array} \\
\end{array}$ & 6,1 & $-0,20$ & 125,20 & 57,0 & Southern Molucca Sea \\
\hline
\end{tabular}

Pengujian dari data tersebut dilakukan dengan trial dan error, adapun kedalaman yang digunakan meliputi $0,0 \mathrm{~km}, 20,0 \mathrm{~km}, 30,0 \mathrm{~km}, 40,0 \mathrm{~km}, 50,0 \mathrm{~km}, 60,0 \mathrm{~km}, 70,0 \mathrm{~km}, 80,0$ $\mathrm{km}$, dan 90,0 km. Data input yang digunakan sesuai dengan kebutuhan pada HYPO71PC, yaitu berupa data waktu tiba gelombang $\mathrm{P}$ dan S, data waktu kejadian, data kedalaman, data magnitudo, serta data posisi stasiun. Pengujian dilakukan secara bertahap, dengan melakukan variasi terhadap parameter kedalaman, dimulai dari kedalaman 0,0 km sampai 90,0 km kemudian dilihat hasil luarannya, meliputi jumlah yang memberikan luaran dan keunikan luaran. 
Setelah dilakukan iterasi didapatkan data hasil berupa kuantitas output berdasarkan TFD yang digunakan sebagaimana Tabel 2. Diketahui bahwa tidak semua data memberikan hasil, didapatkan maksimal 12 output data dan minimal 1. Hasil ini dipengaruhi oleh parameter kontrol yang diatur dalam HYPO71PC yang dapat menghentikan proses iterasi jika terdapat nilai yang tidak sesuai dengan parameter ${ }^{[12]}$.

Tabel 2. Kuantitas luaran berdasarkan penggunaan TFD

\begin{tabular}{ccc}
\hline No & TFD (km) & Kuantitas output \\
\hline 1 & 0,0 & 10 \\
2 & 20,0 & 11 \\
3 & 30,0 & 12 \\
4 & 40,0 & 7 \\
5 & 50,0 & 11 \\
6 & 60,0 & 12 \\
7 & 70,0 & 12 \\
8 & 80,0 & 1 \\
9 & 90,0 & 12 \\
\hline
\end{tabular}

Jika dijabarkan berdasarkan data output kedalaman dibandingkan dengan kedalaman mula-mula, maka dapat dilihat bahwa tidak semuanya memiliki solusi yang unik sebagaimana Tabel 3.

Tabel 3. Perbandingan kedalaman data awal dengan output berdasarkan penggunaan TFD

\begin{tabular}{ccccccccccc}
\hline \multirow{2}{*}{ Gempa } & BMKG & & \multicolumn{8}{c}{ Iterasi TFD $(\mathbf{k m})$} \\
& $\mathbf{( k m )}$ & $\mathbf{0 , 0}$ & $\mathbf{2 0 , 0}$ & $\mathbf{3 0 , 0}$ & $\mathbf{4 0 , 0}$ & $\mathbf{5 0 , 0}$ & $\mathbf{6 0 , 0}$ & $\mathbf{7 0 , 0}$ & $\mathbf{8 0 , 0}$ & $\mathbf{9 0 , 0}$ \\
\hline 80209 & 57,0 & - & 20,0 & 30,0 & 149,6 & - & 105,5 & 112,1 & - & 143,2 \\
81020 & 108,0 & - & - & - & - & - & - & - & - & - \\
81116 & 39,0 & 0,0 & 20,0 & 30,0 & 40,0 & 50,0 & 60,0 & 70,0 & - & 90,0 \\
81211 & 142,0 & 0,0 & 20,0 & 30,0 & 40,0 & 50,0 & 60,0 & 15,3 & - & 90,0 \\
100405 & 57,0 & 0,0 & 20,0 & 30,0 & 40,0 & 50,0 & 60,0 & 70,0 & - & 90,0 \\
110215 & 34,0 & - & - & 30,0 & 99,9 & 23,3 & 5,9 & 12,3 & - & 209,4 \\
111213 & 162,0 & 113,4 & 362,1 & 129,1 & 130,9 & 155,1 & 107,5 & 115,4 & - & 130,7 \\
120818 & 10,0 & 0,0 & 65,0 & 30,0 & 40,0 & 50,0 & 60,0 & 70,0 & - & 90,0 \\
121217 & 46,0 & 0,0 & 20,6 & 59,2 & - & 87,7 & 13,0 & 39,5 & - & 42,4 \\
140910 & 54,0 & 0,0 & 20,0 & 30,0 & - & 50,0 & 60,0 & 70,0 & - & 90,0 \\
141115 & 104,0 & 0,0 & 20,0 & 30,0 & - & 50,0 & 60,0 & 70,0 & - & 90,0 \\
150315 & 29,0 & 0,0 & 86,3 & 113,7 & - & 133,8 & 95,5 & 98,1 & - & 128,8 \\
170529 & 13,0 & 0,0 & 20,0 & 30,0 & - & 50,0 & 60,0 & 70,0 & - & 90,0 \\
\hline
\end{tabular}

Berdasarkan Tabel 3 kita dapat mengetahui perbedaan yang cukup besar untuk setiap pengujian kedalaman TFD. Pada penggunaan kedalaman 80,0 tidak ada yang memberikan luaran dan ini dimungkinkan merupakan sebuah anomali. Penyebab utama kemungkinan adalah kondisi data masukan dan parameter pendukung yang diperlukan dalam melakukan linierisasi. Dari data-data tersebut dapat dilihat bahwasanya terdapat tujuh kejadian gempa, ditandai dengan shading, memberikan solusi yang dapat dikatakan tidak unik. Hasil dari iterasi untuk kejadian 81020 tidak diperoleh yang diyakini akibat kondisi data yang tidak baik sehingga tidak dapat dilanjutkan tahap iterasi. Sedangkan untuk kejadian yang memiliki solusi yang unik meliputi 80209, 110215, 111213, 121217, dan 150315 . 
Tabel 4. Nilai RMS dari pengujian kedalaman uji TFD

\begin{tabular}{cccccccccc}
\hline \multirow{2}{*}{ Gempa } & \multicolumn{10}{c}{ Iterasi TFD (km) } \\
\cline { 2 - 11 } & $\mathbf{0 , 0}$ & $\mathbf{2 0 , 0}$ & $\mathbf{3 0 , 0}$ & $\mathbf{4 0 , 0}$ & $\mathbf{5 0 , 0}$ & $\mathbf{6 0 , 0}$ & $\mathbf{7 0 , 0}$ & $\mathbf{8 0 , 0}$ & $\mathbf{9 0 , 0}$ \\
\hline 80209 & - & 1,77 & 1,83 & 1,82 & - & 1,78 & 1,80 & - & 1,79 \\
81020 & - & - & - & - & - & - & - & - & - \\
81116 & 11,69 & 10,48 & 10,96 & 11,0 & 11,05 & 11,06 & 11,06 & - & 11,03 \\
81211 & 0,16 & 0,16 & 0,16 & 0,16 & 0,16 & 0,16 & 0,16 & - & 0,16 \\
100405 & 0,44 & 0,44 & 0,44 & 0,44 & 0,44 & 0,44 & 0,44 & - & 0,44 \\
110215 & - & - & 2,03 & 0,84 & 1,24 & 1,25 & 1,22 & - & 1,43 \\
111213 & 0,35 & 0,61 & 0,35 & 0,35 & 0,36 & 0,35 & 0,35 & - & 0,35 \\
120818 & 6,3 & 0,17 & 0,39 & 1,29 & 1,29 & 1,29 & 1,29 & - & 1,29 \\
121217 & 0,46 & 0,45 & 0,45 & - & 0,46 & 0,45 & 0,45 & - & 0,46 \\
140910 & 0,36 & 0,33 & 0,33 & - & 0,33 & 0,33 & 0,33 & - & 0,33 \\
141115 & 7,05 & 0,35 & 0,35 & - & 0,35 & 0,35 & 0,35 & - & 0,35 \\
150315 & 3,26 & 2,23 & 0,27 & - & 1,77 & 2,24 & 2,22 & - & 2,11 \\
170529 & 3,58 & 0,60 & 0,60 & - & 0,60 & 0,62 & 0,29 & - & 0,29 \\
\hline
\end{tabular}

Berdasarkan data kesalahan Root Mean Square (RMS) diketahui bahwasanya hasil yang baik terletak pada rentang antara 0 - 0,3. Jika terjadi nilai kesalahan RMS lebih dari 0,3, maka untuk kedalaman dikatakan sebagai hasil iterasi yang buruk untuk kedalaman, namun masih layak untuk posisi episenter. Implikasi perhitungan kesalahan RMS terletak pada hubungan antara episenter dan kedalaman fokal itu sendiri. Nilai RMS menunjukkan kualitas episenter dan kedalaman yang diujikan. Namun demikian, kondisi tersebut tidak serta merta memvisualisasikan batas kesalahan aktual di lapangan ${ }^{[2]}$.

Tabel 4 menyatakan bahwa tidak semua kejadian genpa dapat diketahui nilai kedalamannya, hal ini kemungkinan disebabkan oleh dua hal utama, yaitu data masukan dan parameter. Selain itu pada kejadian 81116 dengan nilai RMS kesalahan sebesar 11,03 dan diyakini tidak dapat diterima, kemudian dari data hanya didapatkan satu buah data kejadian yang memberikan RMS kurang dari 0,3 pada kejadian gempa 81211. Jika merujuk pada kondisi RMS tersebut maka hasil ini adalah yang terbaik, namun jika kita merujuk pada Tabel 3 terkait hasil iterasi terhadap kedalaman kondisinya menjadi tidak baik. Jika kita lihat berdasarkan korelasi data RMS dan keunikan data luaran kedalaman, maka untuk kejadian 80209 luaran terbaik berdasarkan TFD 60 km, 110215 berdasarkan TFD $40 \mathrm{~km}, 111213$ berdasarkan TFD $50 \mathrm{~km}, 121217$ berdasarkan TFD $50 \mathrm{~km}$, dan 150315 berdasarkan TFD $30 \mathrm{~km}$.

Secara umum penggunaan TFD mempengaruhi luaran kedalaman dan TFD dengan luaran terbaik adalah yang mendekati rentang nilai tengah dari kedalaman yang dominan dari data yang dianalisa. Pendekatan menggunakan parameter uji telah dilakukan dalam banyak kasus, adapun beberapa aplikasinya diantaranya dengan memberikan parameter sumber seismik uji untuk merelokasi gempa di Pidie Jaya Mw 6,5 ${ }^{[13]}$, solusi mekanisme fokal di wilayah Himalaya $^{[14]}$, penentuan model kecepatan 1 dimensi di $\operatorname{Iran}^{[15]}$, juga pada proses penentuan model kerak dangkal serta hiposenter dari data kegempaan di gurun Mojave, California ${ }^{[16]}$. Ketidakpastian dari parameter hiposenter sendiri dapat diestimasi dengan memberikan gangguan khusus terhadap parameter-parameter hiposenter ${ }^{[17]}$. 


\section{KESIMPULAN}

Kedalaman fokal uji mempengaruhi hasil kuantitas dan kualitas luaran proses iterasi pada HYPO71PC. Kondisi terbaik didapatkan ketika iterasi menggunakan TFD rata-rata atau yang mendekati dari kedalaman yang sering ditemukan pada zona data yang dianalisa.

\section{UCAPAN TERIMAKASIH}

Kami mengucapkan terimakasih kepada Direktorat Riset dan Pengabdian Masyarakat, Direktorat Jenderal Penguatan Riset dan Pengembangan Kementerian Riset, Teknologi, dan Pendidikan Tinggi Republik Indonesia atas pendanaan terhadap penelitian kami serta BMKG yang telah memberikan akses data penelitian. Selain itu diucapkan terimakasih kepada pengembang $\mathrm{SAC}^{[10]}$ dan $\mathrm{HYPO} \mathrm{PC}^{[2]}$ telah memberikan ijin penggunaan program dalam pelaksanaan penelitian.

\section{DAFTAR PUSTAKA}

1 Hurukawa, N. 2012. Practical Analyses of Local Earthquake. IISEE: Tsukuba, Japan.

2 Lee, W. H. K., \& Valdes, C. M. 1985. HYPO71PC: A personal computer version of the HYPO71 earthquake location program. US Geological Survey.

3 Klein, F. W. 1978. Hypocenter location program HYPOINVERSE. US Geological Survey.

4 Lienert, B., Berg, E., \& Frazer, L. 1986. HYPOCENTER: An earthquake location method using centered, scaled, and adaptively damped least squares. Bulletin of the Seismological Society of America, Vol. 76, No. 3, Hal. 771-783.

5 Douglas, A. 1967. Joint epicentre determination. Nature, Vol. 215, Hal. 47-48.

6 Hurukawa, N., \& Imoto, M. 1990. Fine Structure of an Underground Boundary between the Philippine Sea and Pacific Plates beneath the Kanto District, Japan. Zisin (Journal of the Seismological Society of Japan), Vol. 43, No. 3, Hal. 413-429.

7 Crosson, R. S. 1976. Crustal structure modeling of earthquake data: 1. Simultaneous least squares estimation of hypocenter and velocity parameters. Journal of Geophysical Research, Vol. 81, No. 17, Hal. 3036-3046.

8 Koketsu, K., Miyake, H., Afnimar, \& Tanaka, Y. 2009. A proposal for a standard procedure of modeling 3-D velocity structures and its application to the Tokyo metropolitan area, Japan. Tectonophysics, Vol. 472, No. 1-4, Hal. 290-300.

9 Xu, L.-S. \& Chen, Y.-T. 1997. The effect of focal depth error on moment tensor inversion. Acta Seismologica Sinica. Vol. 10, No. 5, Hal. 571-580.

10 Goldstein, P., Dodge, D., Firpo, M., Minner, L., Lee, W. H. K., Kanamori, H., ... \& Kisslinger, C. 2003. SAC2000: Signal processing and analysis tools for seismologists and engineers. The IASPEI International Handbook of Earthquake and Engineering Seismology Elsevier. Vol. 81, Hal. 1613-1620.

11 Papazachos, C., \& Nolet, G. 1997. P and S deep velocity structure of the Hellenic area obtained by robust nonlinear inversion of travel times. Journal of Geophysical Research: Solid Earth (1978-2012), Vol. 102, No. B4, Hal. 8349-8367.

12 Kayal, J. 2008. Microearthquake seismology and seismotectonics of South Asia.

13 Supendi, P., Nugraha, A. D., \& Wijaya, T.A. 2017. Relocation and focal mechanism of aftershocks Pidie Jaya earthquake (Mw6. 5) Dec 7th, 2016 using BMKG Network. Jurnal Geofisika, Vol. 15, No. 3, Hal. 17-20. 
14 Kumar, R., Gupta, S. C., \& Kumar, A. 2015. Determination and identification of focal mechanism solutions for Himalayan earthquakes from waveform inversion employing ISOLA software. Natural Hazards, Vol. 76, No. 2, Hal. 1163-1181.

15 Kianimehr, H., Kissling, E., Yaminifard, F., \& Tatar, M. 2018. Regional minimum 1D P-wave velocity model for a new seismicity catalogue with precise and consistent earthquake locations in southern Iran. Journal of seismology, Vol. 22, No. 6, Hal. 1529-1547.

16 Hileman, J.A. 1979, Inversion of phase times for hypocenters and shallow crustal velocities, Mojave Desert, California. Bulletin of the Seismological Society of America, Vol. 69, No. 2, Hal. 387-396.

17 Chen, H., Chiu, J. M., Pujol, J., Kim, K., Chen, K. C., Huang, B. S., Yeh, Y. H., \& Chiu, S.C. 2006. A Simple Algorithm for Local Earthquake Location Using 3D VP and VS Models: Test Examples in the Central United States and in Central Eastern Taiwan. Bulletin of the Seismological Society of America. Vol. 96, No. 1, Hal. 288305. 